\title{
The GLOSS Delayed Mode Data Centre and the GLOSS Implementation Plan 2012
}

\author{
ELIZABETH BRADSHAW ${ }^{1}$, LESLEY RICKARDS ${ }^{1}$, SIMON HOLGATE $^{2} \&$ \\ THORKILD AARUP ${ }^{3}$ \\ 1 British Oceanographic Data Centre, Joseph Proudman Building, 6 Brownlow Street, Liverpool L3 5DA, UK \\ elizb@bodc.ac.uk \\ 2 Sea Level Research Foundation, Liverpool Science Park IC1, 131 Mount Pleasant, Liverpool L3 5TF, UK \\ 3 Intergovernmental Oceanographic Commission of UNESCO, 1 rue Miollis, 75732 Paris cedex 15, France
}

\begin{abstract}
The main component of the Global Sea Level Observing System (GLOSS) is the GLOSS Core Network (GCN) of 290 sea level stations. The present definition of the GCN (the definition is modified every few years) is called GLOSS10. In 2012 a new GLOSS implementation plan was developed to update technical standards for GLOSS tide gauge stations, as well as describing the basic terms and obligations for Member States participating in GLOSS. The British Oceanographic Data Centre (BODC) and the Permanent Service for Mean Sea Level (PSMSL) run the GLOSS Delayed Mode Data Centre jointly. It is responsible for assembling, quality controlling and distributing the "final" version of GLOSS sea level data sets and their supporting metadata, as well as carrying out data archaeology on historical analogue sea level records, preserving them in digital form. It also maintains the GLOSS Station Handbook and GLOSS website.
\end{abstract}

Key words sea level; observing system; data; data centre; delayed mode; data archaeology

\section{WHAT IS GLOSS?}

The Global Sea Level Observing System (GLOSS) is an international programme conducted under the auspices of the Joint Technical Commission for Oceanography and Marine Meteorology (JCOMM) of the World Meteorological Organisation (WMO) and the Intergovernmental Oceanographic Commission (IOC).

GLOSS was established in 1985 by an IOC Task Team of interested scientists led by Dr David Pugh from the Proudman Oceanographic Laboratory (now the National Oceanography Centre) and Prof. Klaus Wyrtki from the University of Hawai'i. The aim was to provide support and coordination for international and regional sea level science and to improve the quantity and quality of Mean Sea Level (MSL) data supplied to the Permanent Service for Mean Sea Level (PSMSL) (Fig. 1).

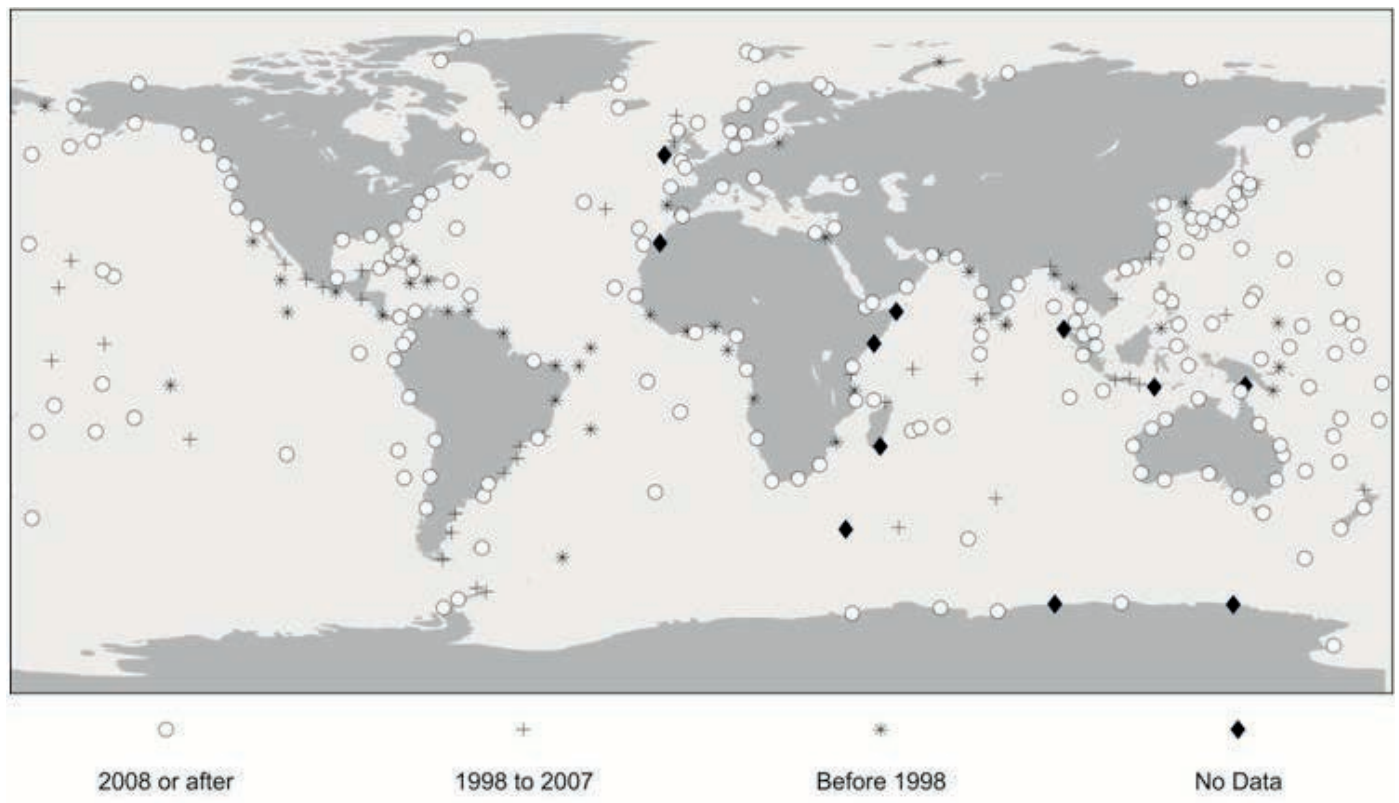

Last year of data

Fig. 1 Status of the GLOSS Core Network (GCN) data in the PSMSL database. 
Sea level data are vital to scientists studying major ocean currents and global climate change, to engineers designing coastal installations, to those engaged in operational oceanography (e.g. provision of flood warnings from storm surges or tsunamis) and in local applications such as provision of tide tables. In many of these applications the rapid exchange of reliable data, nationally, regionally and even globally, can increase the value of the work.

\section{THE GLOSS IMPLEMENTATION PLAN}

The first GLOSS Implementation Plan (GIP), published in 1990, established the GLOSS Core Network (GCN) of approx. 300 tide gauges distributed around the world, as well as technical standards for GLOSS tide gauge stations and the basic terms and obligations for Member States participating in GLOSS (Intergovernmental Oceanographic Commission, 1990). The definition of the GCN is modified every few years, and the present definition, GLOSS10, contains 290 sea level stations (Fig. 2). The Core Network is designed to provide an approximately evenly-distributed sampling of global sea level variations and several stations were replaced in the present definition to make the network more robust. New data recording and transmission technologies, e.g. tide gauges that measure via radar, may mean that stations can now be set up in locations that had previously been considered impractical to monitor.

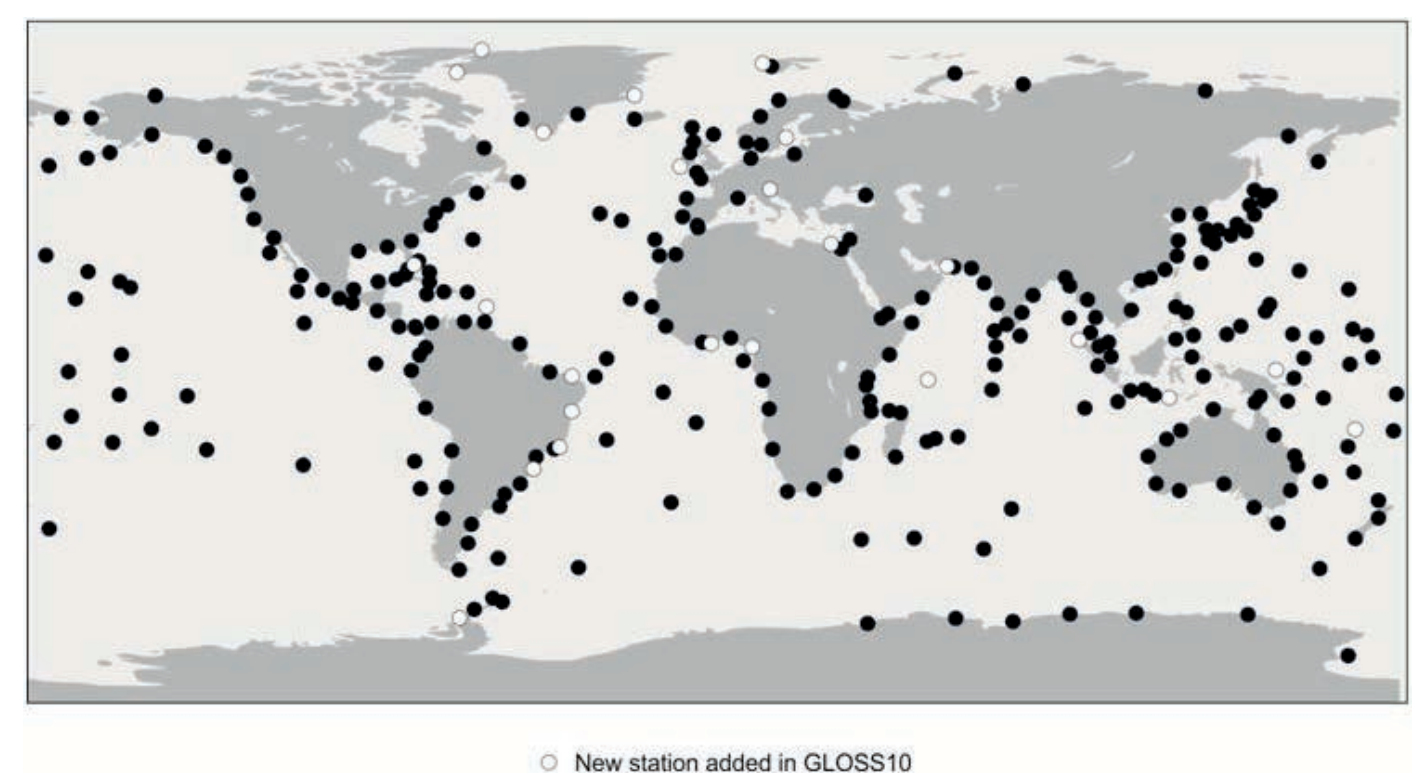

Fig. 2 The GLOSS Core Network (GLOSS10).

A new GLOSS implementation plan was published in 2012 (Intergovernmental Oceanographic Commission, 2012) and called for two significant upgrades to the sea level stations in the GCN. These are: that all GCN stations should report data in near real-time and that all stations should have continuous global navigation satellite system (GNSS) measurements in the vicinity of the tide gauge benchmark (TGBM). The benefit of converting all GCN stations to reporting in near real-time include improved data quality and quantity as problems can be identified and addressed in a timely manner, supporting tsunami and hazard monitoring, and the ability to assimilate tide gauge data into operational models for storm surge and coastal inundation. GNSS measurements of vertical land movement will aid efforts into researching global and regional sea level changes and will support satellite altimetry calibration. Rates of regional sea level rise expected from ocean thermal expansion and ice melting are altered by vertical land movement, which can impact on sea level rise on the coast.

A further new requirement of the implementation plan was that the various GLOSS data centres work towards providing a unified access to the various data streams using relational database tools and cross-referencing techniques to give the feel of a centralised GLOSS web server 
for all data and metadata sets. There are five data streams taking GLOSS tide gauge data and associated parameters from the network's stations to users. Real-time and near real-time data are collected for the purpose of tsunami monitoring systems and storm surge forecasting, as well as for monitoring the status of the gauge itself. Data are sent to the IOC Sea Level Station Monitoring Facility, operated by the Flanders Marine Institute (VLIZ) on behalf of GLOSS. These data are raw, with no quality control performed. Fast delivery data are data that are transmitted to the University of Hawai'i Sea Level Center (UHSLC), normally within one month of collection. These data are mainly used for the calibration of satellite altimeter data and generation of blended products. The data are filtered down to hourly values, and are quality controlled by the UHSLC. Hourly (or sub-hourly) values are supplied to the Delayed Mode Data Centre in the September of the year following collection. Monthly and annual MSL data are sent to the PSMSL, usually by email. Occasionally, the PSMSL will write to tide gauge operators, requesting this MSL data. The data are quality controlled and then made available. The Système d'Observation du Niveau des Eaux Littorales (SONEL) observing service, which is supported by the University of La Rochelle and the French CNRS/INSU institute, provides information about the status of GNSS stations at or near to the GCN stations through a web-based monitoring facility. It assembles, archives and distributes GNSS observations and metadata.

\section{THE GLOSS DELAYED MODE DATA CENTRE}

The GLOSS Delayed Mode Data Centre is operated by the British Oceanographic Data Centre (BODC) in collaboration with the PSMSL (Holgate et al., 2013). It is responsible for assembling, quality controlling and distributing the "final" versions of GLOSS sea level data sets, as well as all supporting metadata, maintaining the GLOSS website and GLOSS Station Handbook. BODC is responsible for high-frequency sea level data and extra parameters, while the PSMSL deals with monthly and annual mean sea level data. The collaboration aids information sharing, eliminates duplication of data and metadata, and increases the data centres' efficiency.

Delayed mode data have a one-year latency, i.e. are made available one year from collection, usually in the September of the following year, and are downloaded from tide gauge operators via the internet, ftp or email, or are received directly from the operator on media such as CDROMs or external drives. The data should be supported by metadata, such as instrumentation information, site location and benchmark information.

For delayed mode data, it is assumed that the data originators will have already performed a certain level of quality control. The data collated by the delayed mode data centre are high frequency, with most gauges producing data with a time interval of between 5 and 15 minutes. The dataset also contains other parameters where they have been recorded at tide gauge stations, such as water temperature, air temperature and barometric pressure. The data are quality controlled to common GLOSS delayed mode data standards, to which BODC contributed (Intergovernmental Oceanographic Commission, 2014). The data are converted into a common standard format, QXF, a platform-independent binary format (a subset of NetCDF; Rew \& Davis, 1990) so that they can be stored and distributed more efficiently. Parameter codes are assigned from a controlled vocabulary, as described by Leadbetter et al. (2013) and consistent flags, units and absent data values are assigned. After transfer, the data are screened using BODC's in-house software, Edserplo. The primary quality control of sea level is based on the inspection of both recorded data and meteorological residuals; inspection of residuals is especially useful for detecting instrumental faults such as timing errors, datum shifts and spikes.

The GLOSS website (http://www.gloss-sealevel.org/) was set up in 2006 to provide access to data and metadata for the GCN stations, to act as a repository for reports and to disseminate information about the GLOSS programme. The metadata for all GCN stations is accessed via the GLOSS Station Handbook. The Handbook, maintained by BODC, contains information about the gauges, their surroundings, and the tide gauge operators. There are maps, photographs and important benchmark information. Where available there are also links to data. In 2012/2013 there were over 12000 visitors to the GLOSS website. 


\section{GLOSS SEA LEVEL DATA ARCHEOLOGY}

In 2001, GLOSS and the International Oceanographic Data and Information Exchange (IODE) programme initiated a data archaeology project that aimed to rescue sea level information that existed only in analogue form (charts, paper tape, etc.) and convert it to a digital format. A letter and questionnaire was circulated to GLOSS members, requesting that they assess their holdings of potentially rescuable historical tide gauge data. BODC has been involved in sea level data archaeology through GLOSS, including distributing the questionnaires on analogue data holdings, contributing to conference posters and presentations, and providing advice to the GLOSS Group of Experts.

In 2006, the World Climate Research Programme (WCRP) convened a workshop "Understanding Sea-Level Rise and Variability" to identify the uncertainties associated with past and future sea level rise and variability, and determine the research and observational activities needed for narrowing these uncertainties. A summary statement was issued following the workshop and a volume of reviews of each area of sea level science was published (Church et al., 2010). The workshop provided several recommendations to GLOSS, which included: "Pursue data archaeology and complete the GLOSS network of tide gauges, each with high-frequency sampling and real-time data availability, to enable an assessment of the incidence of extreme flooding events."

At the twelfth session of the GLOSS Group of Experts in 2011 the group acknowledged that a large amount of historical data remained in paper form and noted that there had been recent findings in non-oceanographic facilities such as the United States National Archives and Records Administration and the archives of the French territorial divisions. A questionnaire was developed and sent to the GLOSS national contacts, the International Hydrographic Organization national agencies, and was also circulated in the Atmospheric Circulation Reconstructions over the Earth (ACRE) community. Patrick Caldwell, manager for the Joint Archive for Sea Level based at the University of Hawai' $i$ Sea Level Center, published the findings at the UNESCO "The Memory of the World in the Digital Age: Digitization and Preservation" conference and remarked that "a vast amount of historical tide gauge measurements exist in non-electronic form" (Caldwell, 2012).

In 2012, BODC won a grant to digitise historic paper charts (Fig. 3) and scan ledgers (Fig. 4) stretching back to 1853 and created over 160 site-years of digitised chart data from 22 sites and approx. 500 years of scans from 14 UK sites. The analogue records, held in the BODC archive, are now available to the wider community. This work has been funded through the JISC Content programme 2011-2013. The GLOSS website lists various other sea level data archaeology projects around the world and BODC will be taking the lead on a progress report to the Thirteenth Session of the GLOSS Group of Experts identifying automated techniques for the digitisation of archived mareograms.

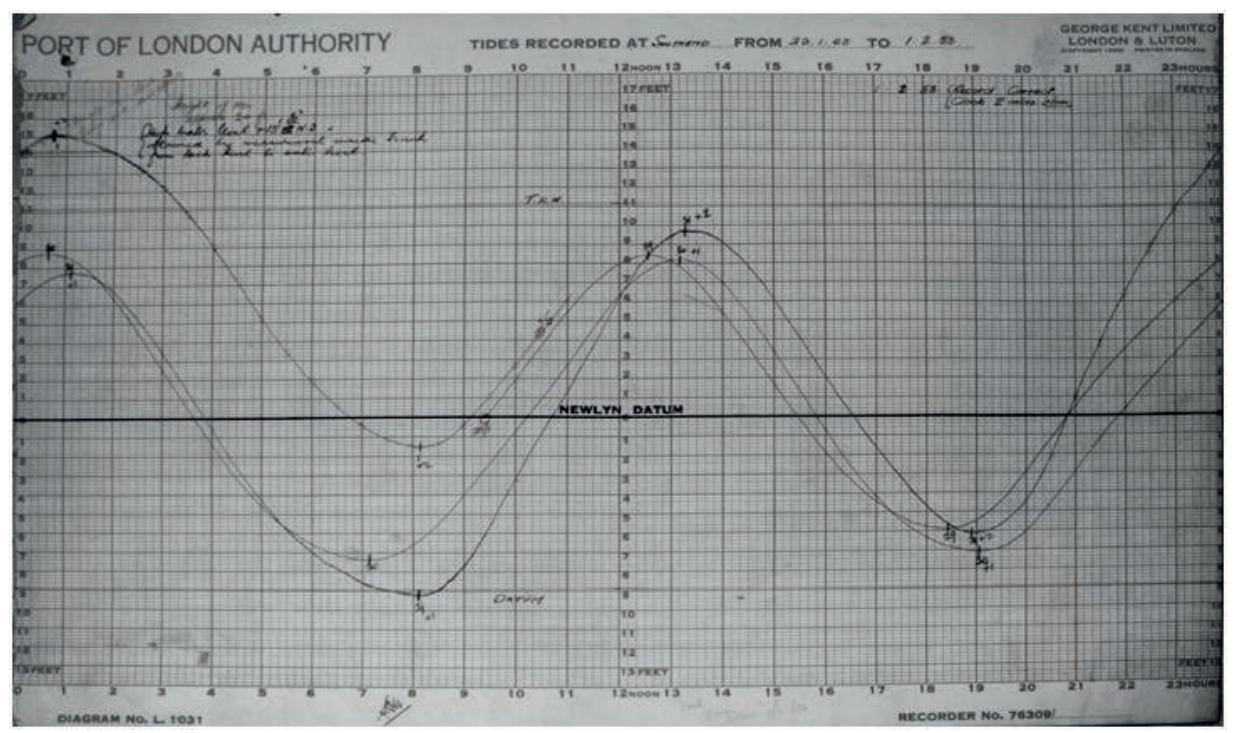

Fig. 3 Example of an analogue tide gauge chart. 


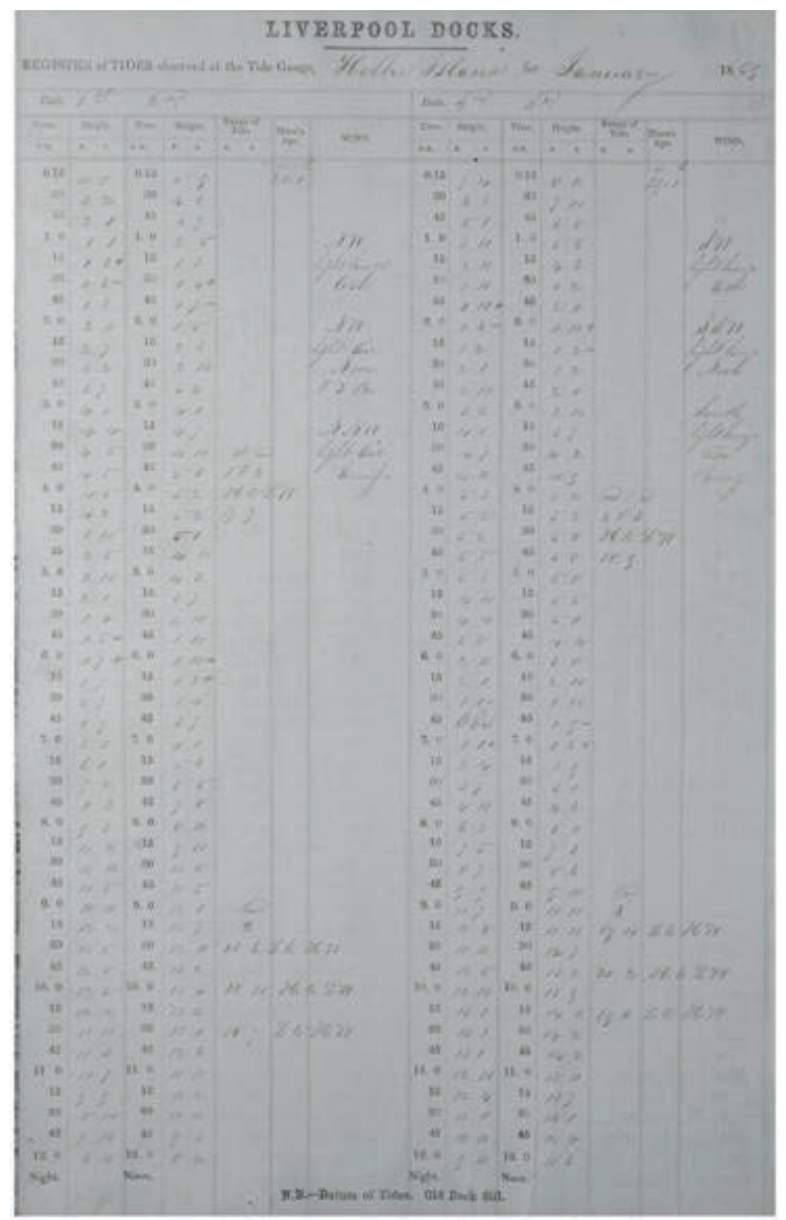

Fig. 4 Scanned ledger from Hilbre Island, 1853.

\section{REFERENCES}

Caldwell, P. (2012) Tide gauge data rescue. In: Proceedings of The Memory of the World in the Digital age: Digitization and Preservation (ed. by L. Duranti \& E. Shaffe), 134-149. UNESCO.

Church, J., et al. (2010) Understanding Sea-Level Rise and Variability. Wiley-Blackwell.

Holgate, S., et al. (2013) New data systems and products at the Permanent Service for Mean Sea Level. Journal of Coastal Research 29(3), 493-504.

Intergovernmental Oceanographic Commission (1990) Global Sea Level Observing System (GLOSS) implementation plan. UNESCO/Intergovernmental Oceanographic Commission, Technical Series, No. 35.

Intergovernmental Oceanographic Commission (2012) Global Sea Level Observing System (GLOSS) Implementation Plan 2012. UNESCO/Intergovernmental Oceanographic Commission, Technical Series, No.100.

Intergovernmental Oceanographic Commission (2014) Manual on Quality Control of Sea Level Observations (ed. by M. J. Garcia et al.). UNESCO/Intergovernmental Oceanographic Commission. Available from: http://iocgoos.org/index.php?option=com_oe\&task=viewDocumentRecord\&docID=8097 (accessed 06 June 2014)

Leadbetter, A., Lowry, R. \& Clements, D. (2013) Putting meaning into NETMAR - the open service network for marine environmental data. International Journal of Digital Earth, 1-18, doi:10.1080/17538947.2013.781243.

Rew, R. \& Davis, G. (1990) NetCDF: an interface for scientific data access. Computer Graphics and Applications, IEEE 10(4), $76-82$. 